\title{
DIFFICULT DIALOGUES AND TRANSFORMATIONAL CHANGE THROUGH CROSS-CULTURAL FACULTY DEVELOPMENT
}

\section{Elizabeth Roderick, University of Alaska Anchorage}

Across the globe, our current way of life is taking us to the edge of the cliff. The systems and consciousness that we have used to try to solve problems are not working. Young people need to think and work in new ways.

- Larry Merculieff, Project Director, Warriors for a New Era

A unique partnership between two universities sought to improve the learning climates on both campuses, making each more inclusive of minority voices and ways of knowing and safer places for the free exchange of ideas. Faculty development intensive workshops introduced a wide range of strategies for engaging controversy through difficult dialogues in the classroom. The process, strategies, and results were documented in a handbook. A second-level intensive workshop tackled difficult dialogues between indigenous communities and the academy. The results were transformative, establishing an atmosphere where all viewpoints were respected and freeing both faculty and students to explore new ideas.

Given the role that higher education needs to play in preparing young people to tackle daunting global and national issues, this call to action could have been issued on any college campus. In this instance, it was

The project described in this chapter was supported by the Ford Foundation Difficult Dialogues Initiative. 
made by an Aleut (Alaska Native) leader at the University of Alaska Anchorage (UAA) during a panel discussion prompted by a joint faculty development project on engaging difficult dialogues in higher education. As we worked to promote civil discourse, safer classrooms, and stronger ties and trust between Alaska Native communities and Western universities through a project funded by the Ford Foundation, faculty and staff discovered that new ideas and ways of approaching problems may be found in the ancient traditions of Alaska's First Peoples.

There were two phases to our efforts, each funded by a separate Ford Foundation Difficult Dialogues grant. The first involved two faculty development intensive workshops aimed at increasing skill levels among faculty for introducing difficult dialogues into the classroom, a Books of the Year program, and the creation of a handbook of best practices for engaging controversial topics in higher education classrooms. The second introduced our faculty to key difficult dialogues between the academy and indigenous communities and to traditional indigenous best practices for teaching and learning. The approaches we used can be adapted anywhere to help faculty connect with other invisible or underrepresented groups, build understanding, open faculty to exciting new (and ancient) approaches to teaching, and improve student learning.

\section{Background}

In 2006, UAA, a public four-year open access institution, partnered with Alaska Pacific University (APU), a neighboring small private university, on a proposal to the Ford Foundation's Difficult Dialogues initiative. As the Ford Foundation website explains, "Difficult Dialogues is a program designed to promote academic freedom and religious, cultural, and political pluralism on college and university campuses in the United States" (www.difficultdialogues.org). One of twenty-six two-year projects funded by the initiative, the UAA/APU program aimed to engage faculty and students in constructive dialogue about sensitive political, religious, racial, and cultural issues. Such cooperation between these two usually competitive campuses was an enormous step in successfully negotiating our own difficult dialogues.

In applying for the Ford Foundation grant, UAA was responding to a survey conducted by UAA psychology professor Claudia Lampman: it had revealed that the majority of UAA faculty members had experienced some form of student harassment in the classroom, ranging from open displays of disrespect or disdain to stalking and threats. These incidents 
had had a measurably negative effect on faculty performance, productivity, and job satisfaction, particularly among female faculty. The study showed that 19 percent of female faculty felt physically afraid, 29 percent grew anxious or depressed, and 33 percent had difficulty sleeping. Fifteen percent suffered a loss in productivity, 13 percent admitted to changing an assignment or their teaching style, and 9 percent dropped a controversial topic altogether (Lampman, Phelps, Bancroft, \& Beneke, 2008). Although some incidents of student harassment of faculty did stem from discussions of controversial topics in class, no clear link was established between those two factors. However, significant numbers of faculty indicated a tendency to avoid or downplay certain topics in class in an attempt to prevent unmanageable classroom tensions from arising. Clearly faculty members needed to understand and deal with harassment more effectively.

There was reason to believe that these encounters were also poisoning the learning environment for students. On the 2006 National Survey of Student Engagement, UAA's benchmark mean scores in the Enriching Educational Experience questions ranked below its Carnegie peers' national scores. Students reported few, if any, serious conversations with others who have different religious beliefs, political opinions, or personal values or who come from a different race or ethnicity. More alarming, they ranked the university low on encouraging such contacts.

\section{Learning How to Talk}

Before we could engage successfully with controversial topics in or out of the classroom, we needed training. Faculty come to the university as experts in their fields, but many do not have much training on how to teach and little, if any, preparation on how to deal effectively with, let alone introduce, controversy in the classroom. "If we want our universities to remain vital training grounds for engagement in a democratic society, we must model ways to conduct civil discourse in the classroom," Lauren Bruce, director of the UAA Center for Advancing Faculty Excellence, wrote about the project (Landis, 2008, p. v). To build faculty skills and support for engaging tough topics in the classroom-whether those topics involved gay marriage, resource development, or racismwe decided to design and offer two week-long faculty development intensives.

A faculty committee from both campuses and a variety of disciplines (rhetoric, religious studies, communication, and Alaska Native studies) designed the intensive curriculum; committee members also served as 
presenters during the intensive itself. The curriculum addressed academic freedom, how to prevent or respond to disruptive students, and multicultural ways of knowing, in addition to a wide variety of strategies and techniques for introducing controversial topics and conducting effective civil discourse in the classroom.

Faculty members from both universities applied to participate and were paid for their time. Thirty-two fellows, representing both relatively new and seasoned professors, were selected from eighteen disciplines across the two institutions. The goal was to create a committed cohort that would attend the intensive and serve as a support network for each other after the project concluded. Participants were contractually obligated to apply, document, and assess what they learned in their classrooms the following year; engage students in one or more difficult dialogues; and field-test one or more new techniques. They were also required to submit at least two short reflective essays on strategies, topics, or philosophical issues related to teaching controversial topics and report on their experiences to their colleagues. Finally, participants needed to organize and conduct one university or community workshop on a topic related to difficult dialogues.

We used group exercises extensively in the intensive; faculty became learners of the structures and strategies proposed for possible use in their own classrooms. We began with the strategies outlined in Discussion as a Way of Teaching: Tools and Techniques for Democratic Classrooms (Brookfield \& Preskill, 2005), which served as the text for the faculty intensives.

Week-long faculty development intensives were chosen as a format because they afforded participants and designers two key things. The first was the luxury of time. Academic life makes relentless demands on faculty time. Taking on a new challenge that requires deep learning, and sometimes unlearning, takes focus and, above all, time. The week-long format allowed faculty the time to absorb the new material and consider how to apply it in their courses, practice new skills with peers, and process the emotional and intellectual challenges evoked by controversial topics. The format also provided faculty the opportunity to bond with a new cohort and develop the sense of safety needed to allow themselves to be vulnerable and honest enough to take meaningful risks. With sufficient grounding in the material, the group formed ongoing learning communities and support networks within and across the two campuses.

The second was a mechanism for overcoming faculty resistance to addressing certain topics, particularly race. The intensive was promoted to faculty as an opportunity to learn skills and strategies for addressing controversial topics in the classroom. Faculty who applied were asked to 
indicate the kinds of issues they wished to address. Due to the range of disciplines represented by selected participants, the topics of interest were wide ranging, including environmental controversies, evolution, racism, and gender-related issues. Faculty who attended rarely had much awareness of, or exposure to, the kinds of controversial topics and difficult dialogues (or even disruptive student behaviors) that colleagues in very different disciplines might encounter on a routine basis. Someone who teaches physics, for example, might never have had the time or opportunity to think deeply about issues related to gender, whereas an English professor might not have given much thought to the challenge of responding to evangelical Christian students who attack the theory of evolution.

Inviting faculty to participate in a week-long intensive in which all of these difficult dialogues were addressed allowed them to become better acquainted with the range of controversies and challenges facing the academy. It also ensured that faculty who might usually decide that "that topic [say, race and racism] has nothing to do with my subject or students or teaching" would have the opportunity to participate in discussions and exercises that could begin to clarify the relevance of these issues to all learning communities at the universities. Such challenging topics, in which faculty might be required to more deeply explore their own biases and how those biases might affect their teaching and students, were placed midway through the week. Doing so ensured that participants would have established some sense of safety and community and that they had sufficient time invested in the project so they were less likely to drop out if things became uncomfortable.

\section{Shared Texts as Catalysts for Difficult Dialogues}

Concurrently with participants' efforts to apply what they learned in their classrooms, the two universities launched a Books of the Year program in which selected texts served as a framework and catalyst for guided explorations on common controversial topics. The books selected that first year were The Spirit Catches You and You Fall Down (Fadiman, 1997) and The Tortilla Curtain (Boyle, 1995), both of which address multiculturalism, immigration, assimilation, and otherness. Events included public forums, guest speakers, art programs and performances, and faculty development workshops on best practices for teaching the selected books. Reader's guides were developed for each book to help guide discussions. Faculty voluntarily included all or part of the books in their syllabi.

"We use our Books of the Year program to provoke serious discussions at all levels throughout the curriculum," explained John Dede, special assistant to the senior vice provost at UAA, one of the administrators in 
the project. The discussions created cross-disciplinary interactions that had rarely occurred among faculty. It even produced some novel interactions between classes. For example, two philosophy courses joined forces to have their students role-play scenes from the Fadiman book, with students teaming up to represent various characters in the book and improvising sequels to incidents described in it. Students were so enthusiastic that they stayed after class for an extended period of time, continuing the discussion.

UAA and APU are now in the fifth year of the Books of the Year program. Subsequent themes have included religion and politics, Alaska Native issues, and responding to climate change. The 2010-2011 theme is service in a foreign land, which explores the responsibility of the individual to other human beings. The books are This Is Not Civilization (Rosenberg, 2004) and Mountains Beyond Mountains (Kidder, 2004).

\section{Sharing What We Learned}

After a year of using the new pedagogical tools, it was time to share what we had learned. Faculty experiences, curricula, materials, and resources, as well as insights from the facilitator, were compiled into an easy-touse manual aimed at faculty, Start Talking: A Handbook for Engaging Difficult Dialogues in Higher Education (Landis, 2008). This best practices handbook was distributed to faculty at both universities and to selected universities nationwide.

As project director, I have been invited to speak to faculty and faculty developers across the country about the program. Everywhere I travel, people are hungry for resources to help them effectively engage students, colleagues, and communities in the most critical issues of the day. Those issues often involve charged and challenging discussions between individuals or groups with very different perspectives and backgrounds. Higher education is one of the only places in which we can both model for and train each new generation how to respectfully and civilly engage in the give-and-take between diverse viewpoints and populations so necessary for a healthy democracy.

\section{Assessing Our Efforts}

We used four methods to assess the initial project:

1. A pre- and posttest during the faculty intensive, and a test a year later of participant perceptions of their new skills and knowledge of difficult dialogues practice and of the roles and responsibilities related to academic freedom 
2. End-of-term evaluations of student outcomes in those classes testing difficult dialogue techniques

3. Extensive qualitative review and self-assessment by participating faculty members

4. Qualitative assessments by staff of the campus and community activities centering upon the Books of the Year

The data showed that faculty members felt significantly more knowledgeable, well prepared, and confident about facilitating discussions on difficult or controversial topics. There was also significant improvement in a faculty member's likelihood of teaching controversial issues. Significant gains were also noted in the ability to create inclusive classrooms where students could safely talk about issues without fear of being sanctioned by other students or the teacher. The faculty gained significantly greater understanding and confidence in addressing disruptive students in the classroom. The data indicated that the faculty development initiative was so much of a success so that we continued it for two successive cohorts using internal funds.

Student outcomes were also positive, based on end-of-term course evaluations from the classes participating in the project. Students were significantly more comfortable speaking openly about a controversial topic and felt the instructor was effective in creating opportunities for difficult dialogue. Although only 240 out of 500 students completed the evaluations, many others were exposed to the classroom practices and community dialogues generated by our project.

\section{Continuing the Conversation: Difficult Dialogues with Alaska Native Communities}

The positive assessments were encouraging, but even after four faculty development intensives, two Books of the Year programs, and the creation of the Start Talking handbook, everyone felt we had just begun the conversation. This was especially true with respect to the tensions between our Alaska Native communities both on and off campus, which many faculty had become acutely aware of through participating in the intensives. We felt ready to move to a deeper level of dialogue, understanding, and action. The Ford Foundation agreed and included us in the group of thirteen out of the original twenty-six designated for funding for a more focused difficult dialogue.

The two-year renewal grant enabled us to continue introducing the lessons learned through the faculty development intensives and other 
learning communities using the Start Talking handbook. Two faculty from the original intensives conducted a six-session faculty learning community on engaging difficult dialogues based on Start Talking. Faculty who attended five of the six sessions received modest stipends for the purchase of materials at the UAA/APU Consortium Library.

More important, we chose to deepen our focus on a subset of difficult dialogues related to Alaska Native issues and constituencies and incorporated books by and about Alaska Native peoples into the Books of the Year program. The original intensives briefly addressed difficult dialogues related to race, ethnicity, and culture, using Alaska's Native peoples as a case study. For many faculty members, even this degree of focus on issues related to Alaska's indigenous communities (beyond the general concern over improving the retention rate for Alaska Native and other minority students) was new. Most of the professors who teach in Alaskan universities-like most of the general population in the state-come from "Outside" in the "Lower 48" states. Beyond the general concern for retaining Alaska Native (and all other) students, indigenous issues were not something to which our faculty had given much thought.

Alaska Native people make up 16 percent of the total population in Alaska, 8 percent of UAA students, and only 1.6 percent of faculty. They comprise 14 percent of APU's student body, but APU currently has no Alaska Native faculty. Both universities have invested significant resources in recruitment and retention measures for this important segment of Alaska's population, though retention rates remain well below the university averages. However, most retention initiatives aimed to make Alaska Native students and faculty more successful within the existing institutional culture. By contrast, the Difficult Dialogues project was designed not only to help non-Native faculty begin to understand and introduce into their courses key difficult dialogues between Alaska's Native communities and Western institutions of higher education, but also help them begin to incorporate traditional Alaska Native ways of teaching and learning into their teaching repertoires. The purpose of the latter focus was twofold: (1) to preempt or otherwise head off difficult dialogues that need not occur if faculty demonstrated a better understanding of and respect for traditional indigenous worldviews and issues and (2) to open faculty to the possibility that non-Native educators have as much or more to learn from Alaska Native elders, leaders, educators, and community members as indigenous peoples do from the mainstream. The intention was to establish a sense of mutuality so that genuine dialogue (difficult or not) could begin to take place between the two communities. We hoped that offering non-Native faculty a chance to enter 
more deeply into and appreciate the ways of teaching, learning and knowing of an "Other" (in the form of Alaska Native cultures) could also serve as a case study for learning from and interacting respectfully with other forms of difference. Such learning might offer transformational possibilities for higher education-possibilities everyone truly committed to education seeks and, as the Aleut leader cited at the opening to this chapter pointed out, are critical for our times.

\section{Native Ways of Teaching and Learning}

In conjunction with the project director (myself, a white woman), Alaska Native leaders, elders, educators, and community members designed a new faculty intensive using much the same structure as the previous intensives, but centered around Alaska Native issues and learning strategies. We recruited a second cohort of eighteen faculty fellows from among the participants in the previous four Difficult Dialogues cohorts, based on their demonstrated leadership, motivation, and commitment. Again, these fellows were expected to apply what they learned in the classroom, participate in assessment activities, and share their learning with their colleagues. Assignments were given to small groups of faculty to develop strategies for applying several of these ways of teaching and learning in at least one of their courses.

Faculty were introduced to several traditional Alaska Native ways of teaching and learning, including experiential and applied learning, placeand community-based learning, nonverbal learning, storytelling, and an organic earth-based pace, incorporating silences and pauses that provide time to reflect. They also participated in key difficult dialogues between Alaska Native communities and the academy concerning such topics as sustainability of life systems, the role of spirituality in education, the relationship between Western science and research and Alaska Native communities, institutional racism, and the lack of Alaska Native faculty and ways of teaching in the academy.

One day of the intensive took place on tribal lands some twenty miles north of the campuses. Alaska Native elders from four different indigenous nations spoke to the group, and each represented tribe made a presentation about its history and lands. An Alaska Native dance group performed and engaged the faculty in dancing, and faculty members presented nonverbal stories derived from their lives. At the end of the day, the group ate traditional foods together outside on the land. At various times during the week, guest presenters from the Alaska Native community shared their experience and expertise on topics ranging from our 
first-ever Alaska Native charter school for kindergarten to sixth grade, to Alaska Native storytelling, to what our Alaska Native students need today. In addition, Alaska Native faculty and staff participated in a fishbowl exercise in which they shared their experience of institutional racism at one of the universities and how they believe that racism affects Alaska Native students. Interactive theater was employed to help faculty participants grapple with incidents involving institutional racism.

\section{Online Teaching Portfolios}

As a way of ensuring that the learning that resulted from participation in the intensive was not limited to these few faculty members, participants were required to create and post an electronic teaching portfolio based on the principles of the scholarship of teaching and learning (SoTL). They attended two training sessions in SoTL prior to the intensive that were designed to help them think about how best to introduce indigenous content and pedagogies into their courses. They also received technical assistance to help put the portfolios together and upload them onto the website. These portfolios can be viewed at www.uaa.alaska.edu/cafe/ portfolios/index.cfm.

In one portfolio, Dorothy Shepard Dunne of APU describes how she introduced place-based learning and time for reflection into a writing assignment for her online human services course, Discussing Diversity and Discrimination. Each student was asked to find a place outdoors and spend at least an hour alone closely observing the surroundings and letting go of other thoughts. Dunne suggested a breathing exercise to help them let go. After their time outdoors, they were to write down what they had observed in as much detail as they could, how they felt during the exercise, and any meaning found in what they observed. Since the course was offered online, students were located in many different locations, including Virginia. The results were surprising and touching. Several wrote that they had never had this kind of experience before. These busy, plugged-in students had learned a powerful lesson about how to slow down and pay attention. And if they could hear the birds chattering and the sound of their own feet crunching on the brittle fallen leaves, feel the wind brushing their skin, and notice the texture of the clouds and the sky above, maybe they could listen with an open mind and heart to people who might look different than they do or hold a different point of view.

Don Rearden, assistant professor in UAA's College of Preparatory and Development Studies, used a similar exercise in his preparatory writing 
course with equally powerful results. Students deemed highly at risk academically by the institution produced lyrical, impassioned writings that brought tears to the eyes of Rearden's colleagues from the intensive when he shared them at one of the regular support sessions for participants.

\section{A Life-Changing Experience}

Project results have been impressive. UAA's Lampman designed qualitative and quantitative assessment programs for both faculty and students to track success. Pre- and posttests documented significant shifts in attitudes related to teaching strategies. For example, faculty and students increased their belief that slowing the class pace and covering less material at a deeper level would be beneficial for student learning. All groups involved with the intensive were also more likely to endorse the notion that course material should be tied to the sustainability of the earth's systems and that sharing personal stories relevant to class material should be encouraged. In addition, significant numbers of faculty shifted with respect to Alaska Native-specific questions; for example, 65 percent felt that their classrooms were now more likely to be places where all students would feel comfortable talking about Alaska Native issues, and 71 percent agreed more strongly that institutional racism is an important explanation for why some Alaska Native students have difficulty completing college. Qualitative data confirmed the transformative impact that the experience had on faculty, both personally and professionally. One faculty member offered these comments in the postintensive evaluation, "This has been a life-changing intensive . . . the experience will affect not only my teaching, but also my parenting and my citizenship." Another wrote, "This was a perspective-shifting, life-altering experience and I know that it will enable me to do my part in helping all students, and particularly Alaska Native students."

\section{Why Start Talking?}

While one of the primary motivations for the original initiative was to create classrooms safe for students and faculty to explore a full range of ideas and subjects, another reason we invested in this effort was to improve how we teach. Most of us are clear about the value of cross- and intercultural learning for our students, but fewer of us have focused on the similar value of developing cross-cultural faculty development programs. Such programs allow faculty to become temporarily "uncoupled from the 
stream of cultural givens" (Habermas, 1990, p. 162), allowing them to think critically about their own teaching practices and the ways in which they may be culturally bound. They help faculty become more aware of how unconscious biases and assumptions may be shaping our classroom environments and pedagogies in spite of our best efforts. They serve to challenge the ways in which faculty development programs, like teaching practices, can unknowingly serve to reproduce the unequal power structures in educational institutions.

We want to design programs that help faculty ensure that all students succeed, not just those who have already accumulated considerable cultural capital. We want to deliver programs that help faculty prepare students to think critically about the status quo and find ways to make society more just, healthy, and sustainable. It is difficult for faculty to do this if they have not had the opportunity to experience other ways of thinking, seeing, speaking about, and organizing the world themselves. Cross-cultural faculty development programs offer that opportunity.

For example, most faculty rarely consider it part of their responsibility to outline for students the connections between their discipline and the fate of the biosphere on which we depend for continued human existence. In indigenous educational systems, making those connections is central. "Our educational mission is to produce human beings who are at home in their place, their environment, their world," says Yup'ik faculty member Angayuqaq Oscar Kawagley. Native Alaskan educators challenge their mainstream colleagues to reconsider the very purpose of the educational endeavor. If we are not creating human beings who can ensure a sustainable environment for future generations, they ask, then what are we doing?

Learning from Alaska Native educators, community members, leaders, and elders reversed the usual faculty view in which professors tended to see their role as one of "helping" Alaska Native students succeed within the dominant culture. Instead, participants became aware that many indigenous students (and their communities) do not necessarily want to become more like the dominant culture. They learned that many students experience great losses as well as gains by "succeeding" in higher education-losses of language, oral traditions, ties to rural communities and elders, experience in subsistence harvesting practice-and that many elders fear that attending university makes their young people "stupid." Our faculty also learned that if Alaska Native students, communities, and cultures are embraced as full partners in higher education, they can contribute perspectives and practices that could radically improve the educational system for all our students. 
The best practices in teaching and learning of nondominant cultures bring fresh, time-tested ideas into the academy. Some, like active, experiential learning, small group work, and contextualized learning, parallel those identified by Western research as the most effective ways of teaching for most students. Others, like the indigenous focus on shaping citizens aware of their interdependency with and responsibility to the ecosystems that support life, may be different and transformative.

\section{What If You Do Not Have a Specific Minority Group to Work With?}

Many, if not most, faculty development programs do not have a specific minority community with which to work closely to develop an effective cross-cultural faculty development program or module. What can we do in such cases?

First, there are indigenous communities near many universities that are largely invisible to the university community. Invisibility is a key component in the oppression of indigenous peoples, the inevitable result of centuries of policies of assimilation. Begin to research the indigenous nations in your region, where they live, and where their young people attend college. Often a tribal college has been formed because indigenous students do not feel at home in mainstream universities. Identify the indigenous student population at your institution, however small, and reach out to the people and programs that serve them. Ask them to help you find ways to help your faculty learn from those communities and cultures.

Second, begin to build relationships, if you do not already have them, with your faculty of color, international faculty, or community leaders from different cultural backgrounds. Invite them to meet with you to educate you about the best practices in teaching and learning from their cultural backgrounds. Set up opportunities for them to meet with faculty at your institution to share that knowledge. Nurture these relationships over time, and you will begin to develop resources on and off campus for cross-cultural faculty learning.

Finally, in your current faculty development work, emphasize teaching practices that are designed to make learning environments inclusive: varying teaching techniques, permitting multiple ways for learners to show that learning has occurred, using cooperative and collaborative teaching and learning styles, creating occasions for authentic human exchanges, relating course material to learners' lives, using inclusive language, employing problem-solving goals, and asking for feedback from learners about behaviors, practices, and policies that discriminate. These 
approaches and others have been demonstrated to create learning environments in which students "who have been marginalized by the educational system in this culture" (Tisdell, 1995, p. 84) can thrive (Tisdell, 1995; Wlodkowski \& Ginsberg, 1995).

\section{Next Steps}

The purpose of a university is to make students safe for ideas-not ideas safe for students.

-Clark Kerr, former president, University of California

When we began this journey, we were not sure where it would take us. The dedication and belief in the process by university leadership, faculty developers, faculty members, and staff combined to create a process that organically built on itself and led us through each stage. We made progress toward our goals of improving the learning climates on both campuses, making them more inclusive of minority voices and ways of knowing, and providing a safer place for learning and the free exchange of ideas. We discovered that through thoughtful faculty development that built skills to introduce difficult dialogues into and enhance pluralism within our classrooms, we not only touched and challenged students but transformed and energized faculty. By establishing an open atmosphere where all viewpoints and beliefs are respected, we saw firsthand that both faculty and students are freed to explore new ideas and, in the words of our Aleut elder, "Think and work in new ways." Isn't that the role of the university?

\section{How Do You Start Talking?}

- Visit http://difficultdialoguesuaa.org to view Start Talking: A Handbook for Engaging Difficult Dialogues in Higher Education (Landis, 2008). Link to additional resources and campus initiatives, and learn more about the UAA/APU project

- Start a faculty learning community based on Start Talking.

- Become part of the national conversation (www.difficultdialogues. org) about integrating difficult dialogues into higher education across the country. 


\section{REFERENCES}

Boyle, T. C. (1995). The tortilla curtain. New York, NY: Penguin Books. Brookfield, S. D., \& Preskill, S. (2005). Discussion as a way of teaching: Tools and techniques for democratic classrooms (2nd ed.). San Francisco, CA: Jossey-Bass.

Fadiman, A. (1997). The spirit catches you and you fall down: A Hmong child, her American doctors, and the collision of two cultures. New York, NY: Farrar, Straus, \& Giroux.

Habermas, J. (1990). Moral consciousness and communicative action (C. Lenhardt \& S. W. Nicholsen, Trans.). Cambridge, MA: MTT Press. Kidder, T. (2004). Mountains beyond mountains: The quest of Dr. Paul Farmer, a man who would cure the world. New York, NY: Random House.

Lampman, C., Phelps, A., Bancroft, S., \& Beneke, M. (2008). Contrapower harassment in academia: A survey of faculty experience with student incivility, bullying, and sexual attention. Sex Roles, 60(5/6), 331-346. doi:10.1007/s11199-008-9560-x

Landis, K. (Ed.). (2008). Start talking: A bandbook for engaging difficult dialogues in bigher education. Anchorage: University of Alaska Anchorage and Alaska Pacific University.

Rosenberg, R. (2004). This is not civilization: A novel. New York, NY: Houghton Mifflin Harcourt.

Tisdell, E. J. (1995). Creating inclusive adult learning environments; Insights from multicultural education and feminist pedagogy. Columbus, $\mathrm{OH}$ : ERIC Clearinghouse on Adult, Career and Vocational Education.

Wlodkowsi, R. J., \& Ginsberg, M. B. (1995). Diversity and motivation: Culturally responsive teaching. San Francisco, CA: Jossey-Bass. 